\title{
C7-T1 DISC HERNIATION TREATED BY POSTERIOR APPROACH: CASE REPORT
}

\author{
(1) Ahmet SOYER, (1) Hakan SABUNCUOǦLU, (1) Burak KAZANCI \\ Ufuk University Faculty of Medicine, Department of Neurosurgery, Ankara, Turkey
}

\begin{abstract}
C7-T1 disc herniation is a rare condition that constitutes only 4-8\% of all cervical disc herniations. Cases have been treated by anterior and posterior approaches. For the anterior approach, there are many limitations and potential complications. The operation area is close to important visceral structures. So, inadvertent traction and/or dissection can lead to several complications, including oesophageal perforations, vertebral artery injury, pneumothorax and laryngeal/tracheal injuries. The cervicothoracic junction is limited by the manubrium and clavicle bone. A manubriotomy or sternotomy may be required to widen the operation area. This procedure causes patients intense pain despite continuous medications, including narcotics. A posterior approach to C7-T1 disc herniations can be performed with a low rate of complications in appropriate cases.
\end{abstract}

Keywords: C8 radiculopathy, C7-T1 disc herniation, cervicothoracic junction, posterior approach

\section{INTRODUCTION}

Most cervical disc herniations are observed between the C3 to $\mathrm{C} 7$ disc spaces. C7-T1 disc herniation is a rare condition that constitutes only $4-8 \%$ of all cervical disc herniations ${ }^{(1,2)}$. A detailed neurological examination needs to be supported by magnetic resonance imaging (MRI) and electromyogram (EMG) findings for an accurate diagnosis. Cases have been treated by the anterior ${ }^{(3-6)}$, and posterior approaches ${ }^{(7,8)}$ and both have advantages and limitations. We aimed to demonstrate the C7T1 disc herniation treated by the posterior approach.

\section{CASE REPORT}

A 61-year-old male patient presented to our clinic with severe pain and numbness radiating from his neck to the medial side of his right forearm and right digits 4 and 5 . His neurological examination showed hypoaesthesia at both the ulnar side of his right forearm and hand without any motor deficit. His deep tendon reflexes were normal, and Spurling test was positive. His cervical MRI showed a disc herniation that narrowed the right neural foramina at the C7-T1 level (Figure 1). We performed an electrodiagnostic study and confirmed the right C8 radiculopathy. The patient, who had not any benefit from conservative treatment, underwent a " $\mathrm{C} 7$ hemilaminotomy with right T1 foraminotomy" for a posterior approach to the nerve root to be decompressed. Postoperatively, his radiculopathy improved, and his cervical MRI displayed nerve root decompression (Figure 2). He was discharged two days later.

\section{DISCUSSION}

C7-T1 disc herniation is a rare condition among all cervical disc herniations. Most of these disc herniations occur laterally and cause radiculopathy rather than myelopathy because of the absence of Luschka joint at this level ${ }^{(9)}$. A detailed neurological examination needs to be supported by MRI and EMG findings

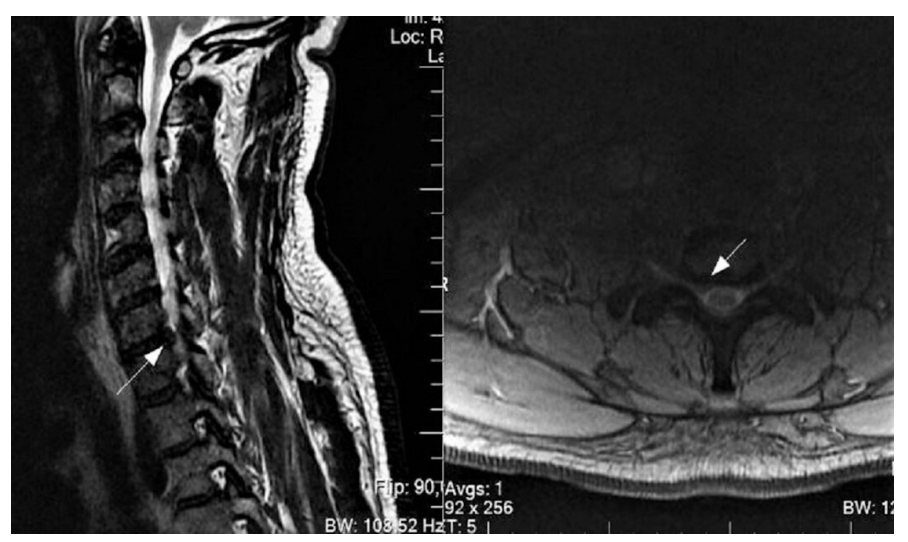

Figure 1. Preoperative cervical MRI showing a disc herniation that narrows the right neural foramina at the C7-T1 level

MRI: Magnetic resonance imaging 


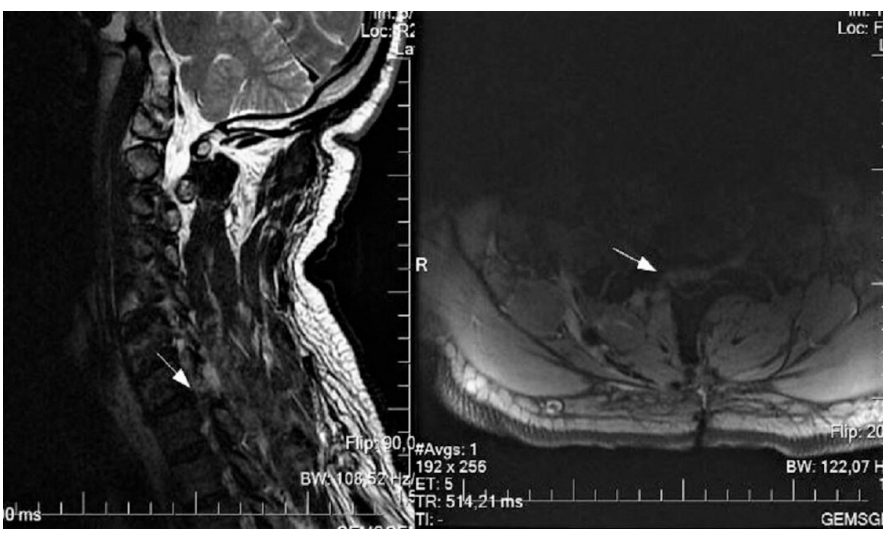

Figure 2. Postoperative cervical MRI displaying nerve root decompression

MRI: Magnetic resonance imaging

for an accurate diagnosis. Surgery can be performed by both an anterior or posterior approach; both techniques have advantages and limitations. The cervicothoracic region can be reached by the anterior approach with the classic supramanubrial Smith-Robinson technique. However, the operation area is close to important visceral structures (trachea, oesophagus, large vessels, ductus thoracicus, sympathetic ganglia) so inadvertent traction and/or dissection can lead to several complications, including oesophageal perforations, vertebral artery injury, pneumothorax, Horner syndrome, dysphagia, dysphonia, hoarseness because of laryngeal/tracheal injuries ${ }^{(7)}$. The cervicothoracic junction is limited by the manubrium and clavicle bone ${ }^{(3,4)}$. A manubriotomy or sternotomy may be required to widen the operation area. This procedure causes patients intense pain despite continuous medications, including narcotics ${ }^{(5)}$. In addition, the cervicothoracic junction is a transition zone from cervical lordosis to thoracic kyphosis, so it is difficult to obtain bone fusion ${ }^{(7)}$. Anterior fusion has been shown to reduce motion by $50 \%$ to $100 \%$, which may improve axial neck pain. This approach, however, may result in increased stress on the adjacent vertebral segments ${ }^{(7,10,11)}$. As compared with the anterior approach, the posterior approach is a relatively safe procedure with a very low rate of complications $(0-4 \%)^{(1,12-}$ 14). Most of them are wound infections and serous drainage ${ }^{(13,14)}$. In conclusion, the posterior approach to C7-T1 disc herniations can be performed with a low rate of complications in appropriate cases.

\section{Ethics}

Informed Consent: The patient signed informed consent form.

\section{Authorship Contributions}

Surgical and Medical Practices: H.S., B.K., Concept: A.S., Design: A.S., Data Collection or Processing: B.K., Analysis or Interpretation:A.S., H.S., Literature Search:A.S., B.K., Writing:A.S. Conflict of Interest: No conflict of interest was declared by the authors.

Financial Disclosure: The authors declared that this study received no financial support.

\section{REFERENCES}

1. Adamson TE. Microendoscopic posterior cervical laminoforaminotomy for unilateral radiculopathy: results of a new technique in 100 cases. J Neurosurg. 2001;95(1 Suppl):51-7.

2. An HS, Wise JJ, Xu R. Anatomy of the cervicothoracic junction: a study of cadaveric dissection, cryomicrotomy, and magnetic resonance imaging. J Spinal Disord. 1999;12:519-25.

3. Cho W, Buchowski JM, Park Y, Maeda T, Nabb CE, Riew KD. Surgical approach to the cervicothoracic junction: can a standard SmithRobinson approach be utilized? J Spinal Disord Tech. 2012;25:264-7.

4. Falavigna A, Righesso O, Betemps A, Vela de los Rios PF, Guimarães $\mathrm{R}$, Ziegler $M$ et al. Surgical planning and neurological outcome after anterior approach to remove a disc herniation at the C7-T1 level in 19 patients. Spine (Phila Pa 1976). 2014;39:E219-25.

5. Lee JG, Kim HS, Ju Cl, Kim SW. Clinical Features of Herniated Disc at Cervicothoracic Junction Level Treated by Anterior Approach. Korean J Spine. 2016;13:53-6.

6. Post NH, Cooper PR, Frempong-Boadu AK, Costa ME. Unique features of herniated discs at the cervicothoracic junction: clinical presentation, imaging, operative management, and outcome after anterior decompressive operation in 10 patients. Neurosurgery. 2006;58:497-501.

7. Harrop JS, Silva MT, Sharan AD, Dante SJ, Simeone FA. Cervicothoracic radiculopathy treated using posterior cervical foraminotomy/ discectomy. J Neurosurg. 2003;98(2 Suppl):131-6.

8. Wang VY, Chou D. The cervicothoracic junction. Neurosurg Clin N Am. 2007; 18:365-71.

9. Yamazaki S, Kokubun S, Ishii Y, Tanaka Y. Courses of cervical disc herniation causing myelopathy or radiculopathy: An analysis based on computed tomographic discograms. Spine (Phila Pa 1976). 2003;28:1171-5.

10. Hilibrand AS, Yoo JU, Carlson GD, Bohlman HH. The success of anterior cervical arthrodesis adjacent to a previous fusion. Spine (Phila Pa 1976). 1997;22:1574-9.

11. Hunter $L Y$, Braunstein EM, Bailey RW. Radiographic changes following anterior cervical fusion. Spine (Phila Pa 1976). 1980;5:399-401.

12. Aldrich F. Posterolateral microdiscectomy for cervical monoradiculopathy caused by posterolateral soft cervical disc sequestration. J Neurosurg. 1990;72:370-7.

13. Henderson CM, Hennessy RG, Shuey HM Jr, Shackelford EG. Posterior-lateral foraminotomy as an exclusive operative technique for cervical radiculopathy: a review of 846 consecutively operated cases. Neurosurgery. 1983;13:504-12.

14. Woertgen C, Holzschuh M, Rothoerl RD, Haeusler E, Brawanski A. Prognostic factors of posterior cervical disc surgery: a prospective, consecutive study of 54 patients. Neurosurgery. 1997;40:724-8. 